\title{
The Roles of Surgical Oncologists in the New Era - Minimally Invasive Surgery for Early Gastric Cancer and Adjuvant Surgery for Metastatic Gastric Cancer
}

\author{
Kazuhiro Yoshida Kazuya Yamaguchi Naoki Okumura Shinji Osada \\ Takao Takahashi Yoshihiro Tanaka Kazuaki Tanabe Takahisa Suzuki \\ Department of Surgical Oncology, Gifu University, Gifu, Japan
}

\section{Key Words}

Gastric cancer • Laparoscopic surgery · Chemotherapy • Adjuvant surgery

\begin{abstract}
In the new era of technical development in surgery, operative devices, molecular targeting and chemotherapeutic agents, surgical oncologists have two main roles in the treatment of gastric cancer. One is to provide patients with minimally invasive surgery, including laparoscopy- or robot-assisted surgery in early gastric cancer patients, and the new concept of surgical intervention toward advanced and metastatic disease. Since recently, laparoscopy-assisted distal gastrectomy has become prevalent in Japan as a surgery which is minimally invasive for the patients and provides them with a good quality of life afterwards. However, the provision of advanced surgical techniques, including lymph node dissection and reconstruction, is more important for patient survival. The second role of surgical oncologists is to evaluate the significant values of the aggressive treatment which we term 'adjuvant surgery' for stage IV gastric cancer patients who have successfully responded to initial chemotherapy for curative intent. Stage IV gastric cancer patients are now being informed about the possibility of longer survival with the new chemotherapeutic and surgical strategic approach.
\end{abstract}

Copyright $\odot 2011$ S. Karger AG, Basel
(C) 2011 S. Karger AG, Basel

1015-2008/11/0786-0343\$38.00/0

Fax +4161306 1234

E-Mail karger@karger.ch

www.karger.com
Accessible online at: www.karger.com/pat

\section{Introduction}

Gastric cancer is the fourth most commonly diagnosed cancer and the second highest in terms of mortality rate. It is a global disease and a type of cancer frequently found in Asian countries. Recent demographic surveys have demonstrated that the mortality rate is notably decreasing, in spite of an only gradual decrease of the occurrence rate $[1,2]$. The major causes of this phenomenon in Japan might be the broad reach of the general screening system of gastric cancer, and secondly, the innovation of newly developed diagnostic systems for the early detection of cancer and the high standard of operative techniques and chemotherapy [3].

According to the Japanese General Rules and Guidelines for gastric cancer $[4,5]$, intramucosal cancers are treated by endoscopic submucosal dissection or endoscopic mucosal resection, and minimally invasive surgery, including laparoscopic gastrectomy, is often performed for the rest of the early gastric cancers which are limited to within the submucosal layer [6-8].

The surgical treatments for stage II and III gastric cancer are well established, as demonstrated by Songun et al. [9] after a 15-year follow-up of the randomized nationwide Dutch D1D2 trial. That is to say, D2 lymphadenectomy is the recommended surgical approach for

Kazuhiro Yoshida

Department of Surgical Oncology Gifu University

Yanagido, Gifu 501-1194 (Japan)

Tel. +81 58230 6235, E-Mail kyoshida @ gifu-u.ac.jp 


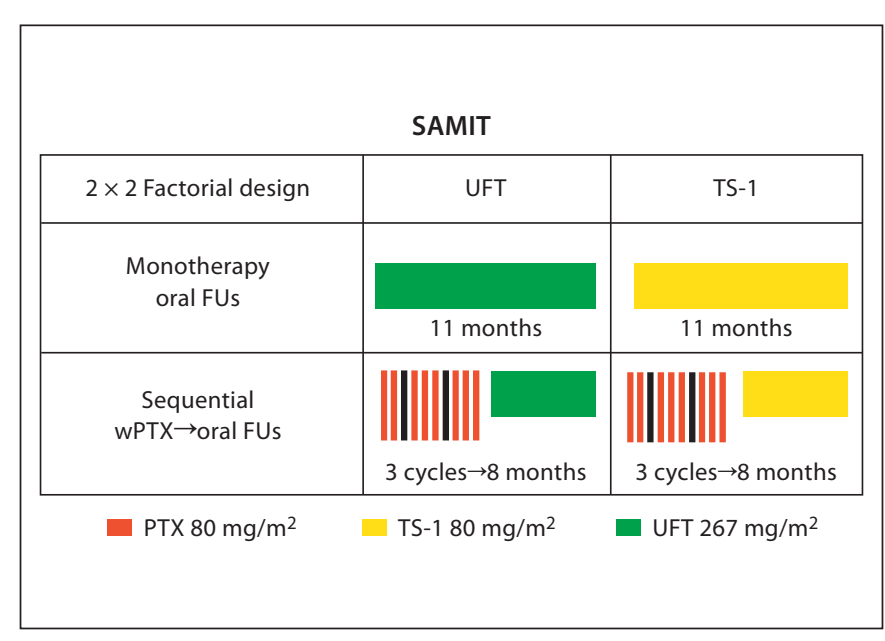

Fig. 1. The rationale of the SAMIT trial. PTX = Paclitaxel.

Table 1. Consensus of perioperative chemotherapy of gastric cancer

\begin{tabular}{ll}
\hline USA & SWOG 9008/Intergroup 0116 \\
& 5-FU/leucovorin + radiation \\
Europe & MAGIC trial \\
& Perioperative ECF \\
Japan & ACTS-GC \\
& Postoperative S-1 \\
\hline
\end{tabular}

patients with resectable (curable) gastric cancer, and is popular in Japan, Korea and other Asian countries. However, postoperative or perioperative treatments remain a controversial issue between the East and the West. Perioperative ECF (epirubicin/cisplatin/5-FU) therapy is regarded as the standard treatment in the UK and in some European countries [10] and intraoperative radiation with postoperative chemotherapy is the widely accepted treatment in the USA [11]. D2 lymph node dissection was not performed in most of the cases in these trials. What was interesting is that the postoperative survival of the patients who underwent D2 lymph node dissection without postoperative chemotherapy in Japan was far better than for those in the Medical Research Council Adjuvant Gastric Cancer Infusional Chemotherapy (MAGIC) trial and Intergroup study [12]. According to the results of the standard procedure of curative surgery, the Adjuvant Chemotherapy Trial of Thymidine Synthase (TS-1) for Gastric Cancer (ACTSGC) was performed for 1 year on stage II and III patients

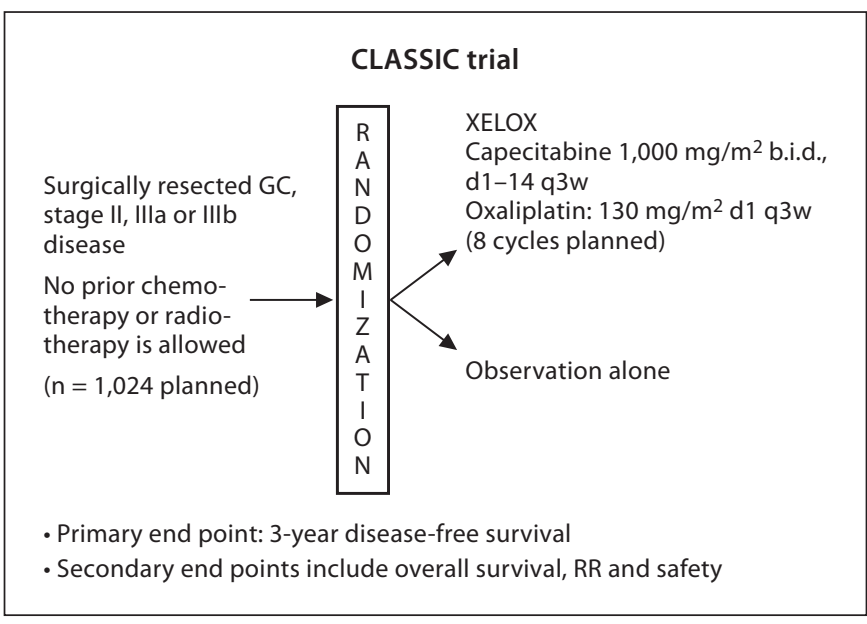

Fig. 2. The rationale of the CLASSIC trial. GC = Gastric cancer; $\mathrm{XELOX}=$ capecitabine in combination with oxaliplatin.

to establish the postoperative S-1 treatment; it was accepted with significant survival benefit of the treatment group in Japan $[13,14]$. The consensus of the perioperative strategies is summarized in table 1 . The Stomach Cancer Adjuvant Multi-Institutional Trial (SAMIT) is currently ongoing; it compares the benefits of S-1 and UFT and also the benefits of adding paclitaxel as adjuvant chemotherapy for curatively resected patients with serosal invasion of a tumor [15]. In Korea, the CLASSIC trial is underway to establish a standard postoperative adjuvant chemotherapy with capecitabine in combination with oxaliplatin after curatively resected stage II and III gastric cancer patients have undergone D2 lymph node dissection [16] (fig. 1, 2).

There is no established global standard chemotherapy for metastatic or recurrent gastric cancer. A combination therapy of fluoropyrimidine and platinum is commonly used [17]. Data is also available about a triplet regimen. ECX (epirubicin/cisplatin/capecitabine) [18], EOX (epirubicin/oxaliplatin/capecitabine) [19] and DCF (docetaxel/cisplatin/5-FU) [20] (or modified DCF [21]) are used as standard care in certain areas of the US and the UK. S-1 combination chemotherapy (S-1 + CDDP) is currently regarded as the standard first-line treatment in metastatic gastric carcinomas in Japan [22]. The median survival time (MST) was prolonged to 13.0 months in the SPIRITS trial conducted in Japan.

As reported at ASCO 2009, a targeted therapy for HER2, Herceptin, was approved for HER2-positive gastric cancer in Europe, Korea and other areas [23]. Other targeted therapies are now under investigation in clinical 
trials. Under these circumstances, we need, via clinical trials, to provide a new treatment which is more effective and has fewer adverse events throughout the world and especially in Asian countries. The data relating to gastric cancer should be obtained by collaboration between Asian countries and transmitted globally to establish a standard treatment because gastric cancer is the most prevalent and common disease in this part of the world.

What is interesting in the recent trend of chemotherapeutic treatment in stage IV gastric cancer is that downstaging of the tumors is often observed with high response rate (RR) regimens with newly developed chemotherapeutic agents, and as a result, $\mathrm{R} 0$ resection (complete resection with no residual microscopic tumor) has been performed on quite a few patients after chemotherapy $[24,25]$. These cases can broadly be called 'adjuvant surgery' or oncosurgery (conversion therapy as it is often described in the treatment of liver metastasis in colorectal surgery) after neoadjuvant chemotherapy [26-28].

Considering the present observations described above, minimally invasive surgery, including laparoscopic surgery or robotic surgery for early gastric cancer [29], and aggressive surgery with curative intent in stage IV, or recurrent gastric cancer with perioperative chemotherapy are the main themes of surgical oncology in the new era. These points are highlighted in this article.

\section{Minimally Invasive Surgery}

\section{Laparoscopic Surgery and Its Indication for Gastric Cancer}

Laparoscopy-assisted distal gastrectomy (LADG), a minimally invasive surgery, has recently become prevalent in Japan, and provides patients with a good quality of life [30-32]. However, it is more important to provide them with advanced surgical techniques including lymph node dissection and reconstruction. According to the Japanese guidelines for gastric cancer treatment, LADG is not regarded as the standard procedure. In order to establish the safety and noninferiority of the method compared to open surgery, randomized control studies in Japan and Korea are ongoing $[33,34]$. For the technical assurance of the laparoscopic surgery, a certification system has been adopted by the Japanese Society of Endoscopic Surgery.

In our institution, the indication for the operation is restricted to patients with early gastric cancer which includes: carcinomas of the mucosal layer (T1), no evidence of lymph node metastasis (N0), not suitable for endoscopic mucosal resection (with a size of more than $2 \mathrm{~cm}$ and with ulcer scar formation), or invaded to the submucosal layer with no clinical lymph node metastasis. Up to October 2010, we performed 204 laparoscopic gastrectomies including 152 LADG, 8 laparoscopy-assisted pylorus-preserving gastrectomies, 21 laparoscopy-assisted proximal gastrectomies, 6 laparoscopy-assisted total gastrectomies and 17 simple resections of the stomach.

\section{Surgical Techniques}

In order to perform complete laparoscopic gastrectomy, resection and anastomosis should be performed in the abdominal cavity. In this section, we describe our standard procedure of LADG and gastroduodenostomy.

We performed 103 cases of gastroduodenostomy using the delta anastomosis technique [30, 35]. Under general anesthesia, the patient was placed in the supine position with legs apart. Initially, a trocar was inserted under the umbilical portion via a $2-\mathrm{cm}$ incision by the open method. Flexible laparoscopy (Olympus) was used in the operation and the camera operator stood between the legs of the patient. Four other trocars were inserted in the flank and subcostal regions.

The operation consisted of 9 parts: (1) ligation of the left gastroepiploic artery and vein [dissection of lymph node (LN) 4d and 4sb], (2) ligation of the right gastroepiploic artery and vein (LN 6), (3) transection of the duodenum, (4) ligation of the right gastric artery (LN 5), (5) dissection of LN 8a, (6) ligation of the left gastric artery and vein (LN 7, 9 and 11p), (7) dissection of LN 1 and 3 , (8) transection of the stomach and (9) reconstruction by the Billroth I method with the delta anastomosis technique. The surgeon stood on the right side except during step (2) and (3).

(1) Ligation of the Left Gastroepiploic Artery and Vein (Dissection of LN 4d and 4sb)

The greater omentum was dissected with harmonic scalpel (Ethicon) about $5 \mathrm{~cm}$ away from the epiploic vessels; LN $4 \mathrm{~d}$ and $4 \mathrm{sb}$ were removed. The left gastroepiploic artery and vein were dissected with clips.

\section{(2) Ligation of the Right Gastroepiploic Artery and}

Vein (LN 6)

The surgeon stood on the left side of the patient to continue the procedure. The greater omentum of the right side was divided in the same manner towards the hepatic flexure of the colon and the gastroduodenal artery was visualized. Dissection of LN 6 was performed, with liga- 


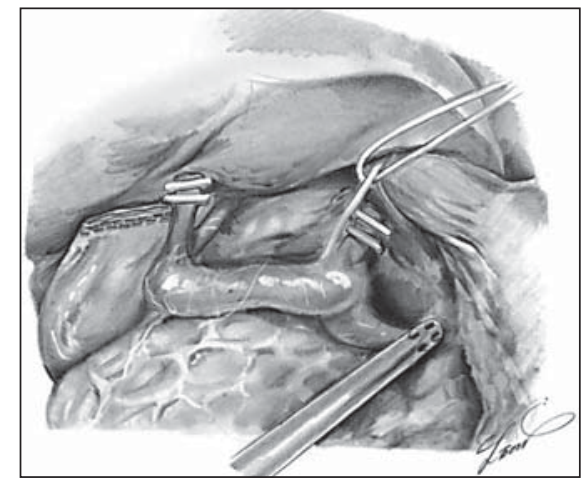

Fig. 3. Lymph node dissection by laparoscopic approach (illustrated by Leon Sakuma [30]).

tion and division of the right gastroepiploic artery and vein by harmonic scalpel.

(3) Transection of the Duodenum and (4) Ligation of the Right Gastric Artery (LN 5)

The surgeon stood on the right side of the patient again. The antrum was lifted and the duodenum was transected close to the pylorus ring using an Echelon (Ethicon) from the left lower port and then the right gastric artery was divided and dissected with the harmonic scalpel with clips cleaning the LN 5.

\section{(5) Dissection of LN 8a}

The stomach was lifted towards the left flank and the lesser omentum was divided visualizing the hepatic branch of the vagus nerve near the liver bed. Preserving the branch, the dissection was performed towards the cardia. The serosa of the right crus was dissected with the harmonic scalpel.

LN 8a was dissected using the harmonic scalpel visualizing the common hepatic artery preserving the hepatic plexus of the autonomic nerve. The dissection was performed from the right side towards the celiac axis (fig. 3).

(6) Ligation of the Left Gastric Artery and Vein (LN 7, 9 and 11p)

The fat tissue and connective tissues of $\operatorname{LN} 8 \mathrm{a}, 7,9$ and $11 p$ were dissected with the harmonic scalpel. The left gastric artery and vein were visualized, then ligated with 2 clips and divided with the harmonic scalpel. The dissection was performed along the curus towards the esophagogastric junction.
(7) Dissection of LN 1 and 3

The dissection of the LN 1 and 3 was performed along the lesser curvature of the stomach, dissecting the anterior and posterior branch of the vagus nerves toward the stomach. The dissection was performed towards the transection line of the stomach.

(8) Transection of the Stomach and

(9) Reconstruction by the Billroth I Method with

the Delta Anastomosis Technique in the Abdominal Cavity

The proximal resection margin was estimated by the serosal side carbon ink color which was injected in the submucosal layer the day before the operation by endoscopy and transected from the left lower port using Echelon $(60 \mathrm{~mm})$. The resected stomach was captured by the end catch and taken out through the camera port with an additional abdominal muscle fascia incision but without an additional skin incision.

For the gastroduodenostomy, the edge of greater curvature of the remnant stomach and the duodenum were opened with the harmonic scalpel and the linear stapler (endcutter $45 \mathrm{~mm}$ ) was inserted via each hole and connected and fired. The V-shape anastomosis of gastroduodenostomy was performed with the entry hole opened. The final step was the closure of the hole with 3 firings of the linear stapler by lifting up the 3 stitches (3-0 monocryl) of incomplete closure of the entry hole (fig. 4).

The mean operative time was $253 \mathrm{~min}$ and blood loss was $50 \mathrm{ml}$. Thirty-seven lymph nodes were harvested. Patients started to walk the next day, started the oral intake treatment on day 3 after the operation and were discharged on day 9. Among 103 cases of delta anastomosis, there was no anastomotic leakage and no reoperation; there were, however, 2 cases of anastomotic stenosis.

Although this procedure requires time and the precise knowledge of the anatomy of the upper abdominal regions, it provides patients with several advantages including improved cosmetics, shorter hospitalization, minimal operative pains and a low incidence of bowel movability and pancreas functions (demonstrated elsewhere). Moreover, the postoperative complications can be reduced. The LADG with lymphadenectomy can be one of the most effective therapeutic methods for early gastric cancer patients. 
Fig. 4. Delta anastomosis (illustrated by Leon Sakuma [30]). a Anastomosis by linear stapler. b Ligation of entry hole. c Closure of entry hole by linear stapler. d Final anastomosis image.

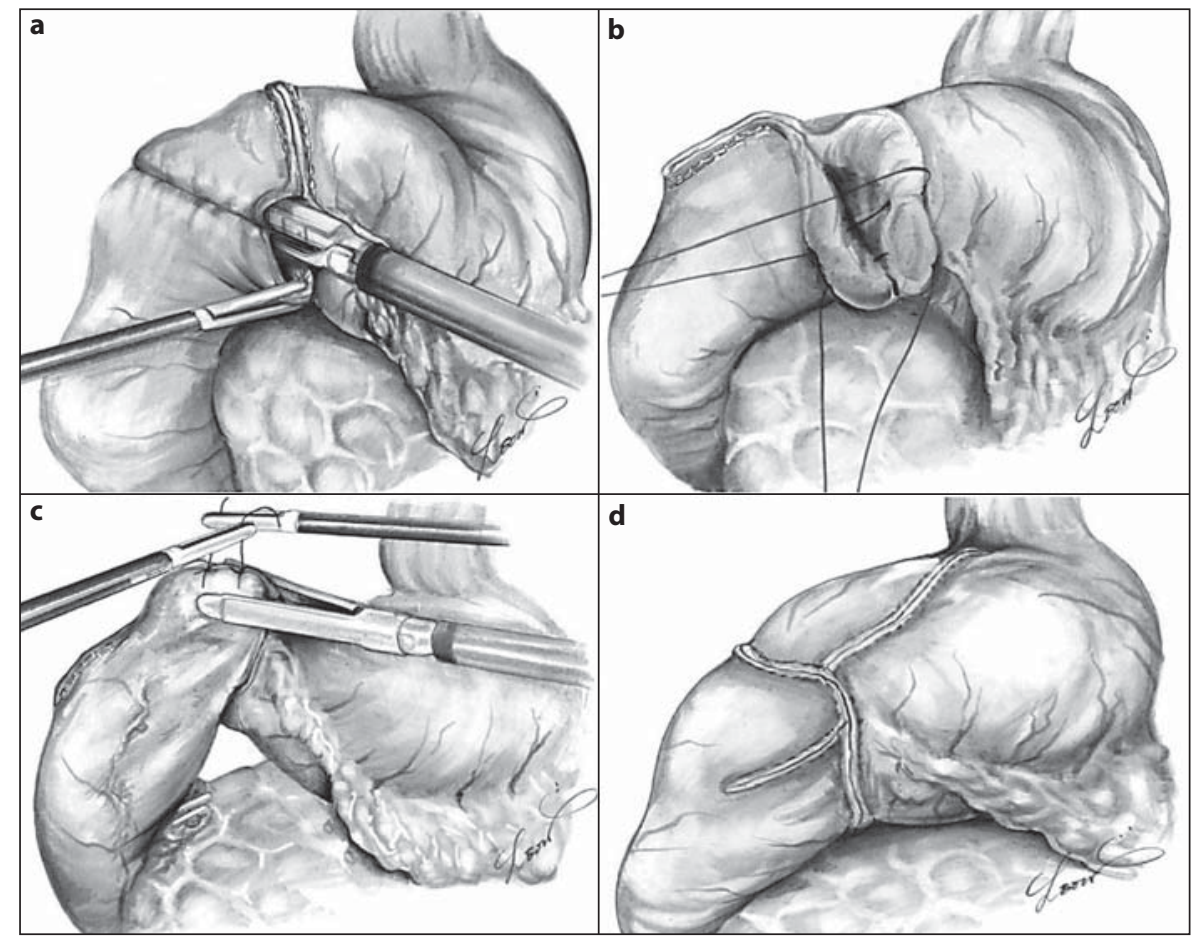

\section{New Therapeutic Approach for Stage IV Gastric Cancer}

\section{Establishment of New Chemotherapeutic Regimens for Gastric Cancer}

Several combination regimens with S-1 have been established in Japan in this decade and randomized phase III studies have been conducted. They are S-1 + CDDP, S-1 + CPT-11 and S-1 + docetaxel as reported by Fujii et al. [36].

Cisplatin at a dose of $60 \mathrm{mg} / \mathrm{m}^{2}$ on day 8 was combined with S-1 for 3-weeks-on and 2-weeks-off treatment [37]. This was repeated every 5 weeks, unless disease progression was observed. The RR was $74 \%$ (14/19; $95 \%$ confidence interval (CI) 54.9-90.6) and the MST was 383 days. Komatsu et al. [38] reported the results of a phase I/II study with CPT-11 + S-1 (IRIS study) in AGC patients. S-1 was given orally twice a day for 14 days and CPT-11 was administered as a 90-min intravenous infusion on days 1 and 15 . This regimen was repeated every 4 weeks. The overall RR was $54.2 \%$ in the phase II study. The MST achieved with this regimen was 581 days. Yoshida et al. $[39,40]$ performed a phase I study and a phase II study of docetaxel in combination with S-1 in patients with AGC. In the phase II study, the RR was $52.1 \%$ and the MST was 434 days. Moreover, the biochemical modulations of docetaxel enhanced the sensitivity of 5-FU in vitro and in vivo [41]. More interestingly, the mTOR inhibitor downregulated the expression of TS and enhanced the reactivity of 5-FU on TMK-1 gastric cancer cells [42].

Based on the results obtained in the above phase II studies, 3 large randomized phase III studies, the SPIRITS trial [22], the TOP-002 trial [43] and the JACCRO GC03 trial $[36,44]$ were conducted independently to compare the data with that of S-1 monotherapy, the results of which are summarized in table 2 .

In the SPIRITS trial, chemotherapy-naïve patients with AGC were randomly assigned to receive either S-1 plus cisplatin or S-1 alone. The primary end point was overall survival and the secondary end points were progression-free survival, proportion of responders and safety. Median overall survival was significantly longer in the patients assigned to receive S-1 plus cisplatin than in those assigned to receive S-1 alone (13.0 vs. 11.0 months, respectively; hazard ratio (HR) 0.77 ; $95 \%$ CI $0.61-0.98$; $\mathrm{p}=0.04$ ). Progression-free survival was significantly longer in the patients assigned to receive $S-1$ plus cisplatin than in those assigned to receive S-1 alone (median progression-free survival 6.0 vs. 4.0 months, respectively; $\mathrm{p}<0.0001)$. Moreover, of the 87 patients with target tumors assigned to receive $S-1$ plus cisplatin, 1 showed a complete response (CR) and 46 showed a partial response 
Table 2. Review of phase III clinical trials in Japan

\begin{tabular}{lllll}
\hline & $\begin{array}{l}\text { S-1/ } \\
\text { S-1 + CPT-11 } \\
\text { (GC0301/TOP-002) }\end{array}$ & $\begin{array}{l}\text { S-1/ } \\
\text { CPT-11+CDDP } \\
\text { (JCOG 9912) }\end{array}$ & $\begin{array}{l}\text { S-1/ } \\
\text { S-1 + CDDP } \\
\text { (SPIRITS trial) }\end{array}$ & $\begin{array}{l}\text { S-1/ } \\
\text { S-1 + docetaxel } \\
\text { (START trial) }\end{array}$ \\
\hline MST, months & $10.5 / 12.8$ & $11.4 / 12.3$ & $11.0 / 13.0$ & $11.0 / 13.0$ \\
\hline 1-year survival rate & $45.0 \% / 52.0 \%$ & $49.7 \% / 52.5 \%$ & $46.7 \% / 54.1 \%$ & $46.0 \% / 52.5 \%$ \\
\hline 2-year survival rate & $22.5 \% / 18.0 \%$ & $-/-$ & $15.3 \% / 23.6 \%$ & $20.6 \% / 23.7 \%$ \\
\hline
\end{tabular}

(PR) (total RR 54\%). Of the 106 patients with target tumors assigned to receive $\mathrm{S}-1$ alone, 1 showed a CR and 32 showed a PR (total RR 31\%). Based on this trial, S-1 plus cisplatin became regarded as a new standard first-line treatment for patients with AGC in Japan.

A randomized phase III trial was conducted to evaluate the efficacy and safety of IRIS (S-1 + CPT-11) versus S-1 alone for AGC. Patients with previously untreated AGC were randomized to arm A (oral S-1, $80 \mathrm{mg} / \mathrm{m}^{2}$ on days 1-28, every 6 weeks) or arm B (IRIS: oral S-1, 80 $\mathrm{mg} / \mathrm{m}^{2}$ on days $1-21$; intravenous CPT- $11,80 \mathrm{mg} / \mathrm{m}^{2}$ on days 1 and 15, every 5 weeks) by dynamic allocation. As a result, 326 patients were randomized to arm A (162 patients) or arm B (164 patients), with a final 315 evaluable patients (160 in arm A and 155 in arm B). Although the MST of the arm A patients was 318 days (95\% CI 286-395) and that of the arm B patients was 389 days (95\% CI 324458), arm B did not show significant superiority to arm A. The RRs were significantly different, being $26.9 \%$ in arm A versus $41.5 \%$ in arm B in 187 RECIST (Response Evaluation Criteria in Solid Tumors)-evaluable patients. Based on this trial, IRIS achieved MST and was better tolerated; however, it did not show significant superiority to $\mathrm{S}-1$ alone in terms of the overall survival, and could thus not become a first-line treatment for AGC.

A randomized phase III study comparing S-1 alone with the S-1 + docetaxel combination was conducted through the JACCRO GC03 trial. This study was a prospective, multicenter, multinational (Korea and Japan), nonblinded, randomized, phase III study of patients with AGC. Patients were randomly assigned to receive 3-week cycles of treatment arm A (docetaxel and S-1) or 6-week cycles of treatment arm B (S-1 only). The primary objective of the study was to compare the median overall survival of the test arm (docetaxel and S-1) with that of the control arm (S-1 only). The secondary objectives were to assess the time to tumor progression (defined as the time from randomization to the date of first documentation of progressive disease), to determine the clinical response/ $\mathrm{RR}$ (defined as the sum of the $\mathrm{CR}$ and $\mathrm{PR}$ according to RECIST criteria) and to evaluate the safety of the 2 regimens. It was expected that 628 patients (314 in each treatment arm) would be enrolled in this trial and this was exceeded, with confirmation of 628 patients from 103 centers in September 2008. Although the primary end point was not met, $\mathrm{PR}$ and RR were superior in the combination arm [44]. What is more interesting in this combination is that the docetaxel enhances the cytotoxic effect of 5-FU via biochemical modulations through decreased expression and activity of TS and dihydropyrimidine dehydrogenase and increased activity of orotate phosphoribosyltransferase [41]. It was recently reported that these effects can be modulated even more by molecular targeting agents including mTOR inhibitor [42].

\section{The Role of Surgical Intervention in Stage IV Gastric Cancer Patients}

\section{Palliative and Volume Reduction Surgery}

Gastric bypass, jejunostomy, ileostomies and colostomies are sometimes performed because of the pyloric stenosis of the primary tumor and/or tumors of the peritoneal disseminated disease of gastric cancer, and often, even if not by $\mathrm{R} 0$ resection, primary tumors are removed because of bleeding or obstruction of the stomach and bowels, all of which are regarded as palliative surgery. In the 1980s, the resection of the primary tumors and the removal of metastatic disease were often conducted as tumor volume reduction surgery. However, the prognosis of patients was not satisfactory because although the main treatment tool was palliative chemotherapy, the RR of chemotherapy regimens in those days was $20-30 \%$ and in the end, the patients died due to the tumor burden in spite of the reduction surgery. In order to improve the survival of the patients, new regimens or new chemotherapeutic 
agents with more effective and reduced adverse effects were called for, but until recently, palliative chemotherapy was regarded as the standard strategy in stage IV or recurrent gastric cancer patients.

\section{Adjuvant Surgery}

As described in the previous section, after the new chemotherapeutic agents were developed including S-1, docetaxel, paclitaxel, irinotecan, oxaliplatin and molecular targeting agents, the RR and survival of patients have improved dramatically. Interestingly, it was often reported that with newly developed chemotherapeutic regimens, the tumors were downstaged and the curative resections or R0 resections were performed in stage IV gastric cancer patients [24]. It is only recently that those cases were often found successful after treatment with S-1 + CDDP and S-1 + docetaxel regimens [45]. These operations are called 'adjuvant surgery' as previously reported [24]. The indications for adjuvant surgery are that curative resection (not palliative) can be expected, based on the response to chemotherapy, the absence or CR of other distant metastases such as peritoneal dissemination, extensive lymph node metastases or lung metastasis. The macroscopically complete removal of liver deposits is feasible, and minimal residual tumors after chemotherapy in distant lymph nodes can be extensively removed. Palliative chemotherapy is the standard strategic approach for stage IV gastric cancer. However, if treatment has been successful with CR or PR and the tumors are considered resectable or R0 resection is deemed possible, it could be feasible to perform aggressive operations to remove the residual tumors, although these operations can be regarded as adjuvant. Of course, it might be required to continue chemotherapy after these surgeries, even after $\mathrm{R} 0$ resections, because these cases were treated as stage IV gastric cancer. This chemotherapeutic strategy is called perioperative chemotherapy [10]. In other words, so-called neoadjuvant chemotherapy (NAC) was performed, downstaging of the tumors followed, and as a result of this, the $\mathrm{R} 0$ resections could take place. It must be clarified that, strictly speaking, NAC is the chemotherapy which is conducted in patients with potentially curative resectable tumors before treatment [46]. NAC is performed in order to improve the prognosis or improve the resectability of the tumors. For aggressive operations in stage IV gastric cancer patients, it can be termed adjuvant surgery with perioperative chemotherapy. The merit of adjuvant surgery in stage IV gastric cancer with a favorable response to chemotherapy is that the compliance with chemotherapy is better before surgery com-

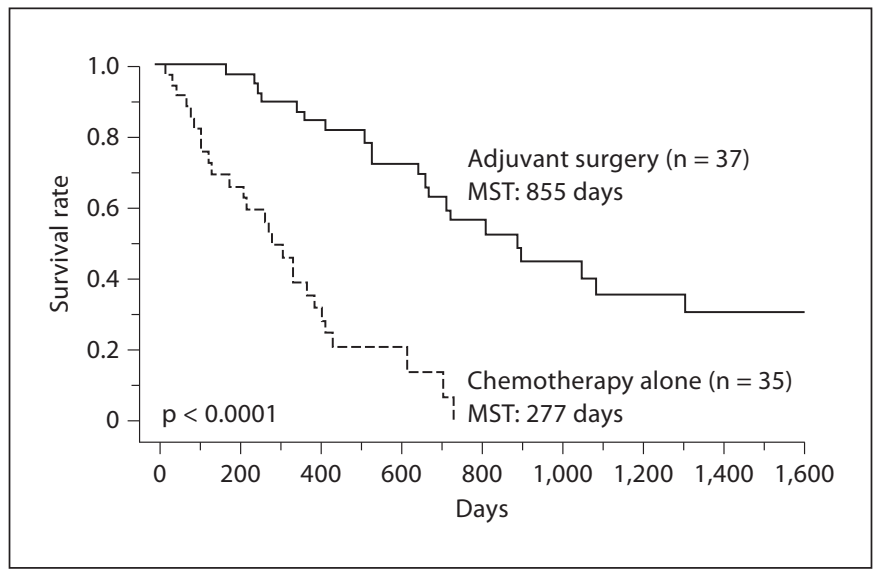

Fig. 5. Survival of the patients with adjuvant surgery in stage IV gastric cancer.

pared to afterwards, and secondly, it can be regarded as an in vivo sensitivity test. Thirdly, tumors definitely acquire resistance to chemotherapy, which is why aggressive operations are preferred while the tumor growth is well controlled with chemotherapy, because it is well known that tumor growth is enhanced by the cytokines after surgical treatment [47]. The best timing for the operation is when the best response of the tumor to chemotherapy is observed, not when the tumor is increasing in size or has acquired the ability to regrow. Generally, we estimate the best timing for the removal of the tumor to be when the CR or PR is detected when 4-6 cycles of S-1 + CDDP or S-1 + docetaxel regimens have been performed. This strategy is regarded as rescue surgery, oncosurgery or conversion therapy (recently conducted in metastatic liver tumors from colorectal cancer) [48-52]. In the REGATTA trial, palliative surgery followed by chemotherapy for stage IV gastric cancer is now being conducted in Japan and Korea in order to evaluate the significant roles of tumor volume reduction and interesting results are expected.

From 2001 to 2009 , we treated 158 stage IV gastric cancer patients who had received S-1 + CDDP and S-1 + docetaxel treatment. We performed adjuvant surgery aiming at $\mathrm{R} 0$ resection of the primary and metastatic disease on 37 of these patients. The median survival of the patients who underwent surgery was 855 days after the initial start of the chemotherapy, while for those without an operation it was 277 days (fig. 5). As we reported in a preliminary retrospective analysis [24], this type of surgery might be effective in patients diagnosed as stage IV 


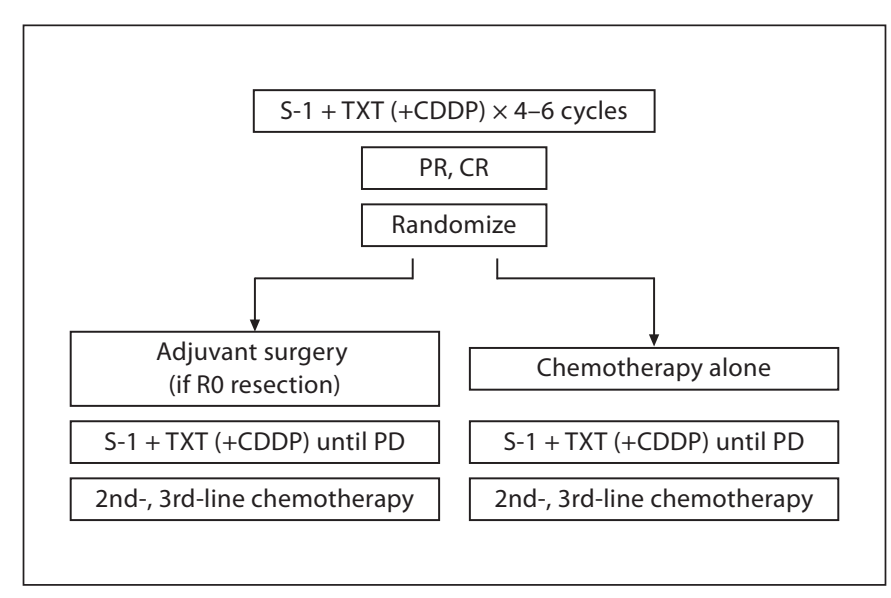

Fig. 6. Future trial of adjuvant surgery. Perioperative chemotherapy in stage IV gastric cancer: a randomized controlled trial of S-1 + docetaxel with or without CDDP. PD = Progressive disease; TXT $=$ docetaxel.

due to liver metastasis or distant lymph node metastasis, but not for cases of peritoneal dissemination. Of course, there is a bias that the adjuvant surgery group had a good response to chemotherapy and the others not. In order to prove the significance of the adjuvant surgery, further analysis will be needed. Under investigation by a ran- domized phase II/III study, using S-1 + docetaxel and/or CDDP among patients who had had CR or PR and were considered curatively resectable, patients were randomized to a 'continuation of chemotherapy' group or an 'adjuvant surgery followed by chemotherapy (perioperative chemotherapy)' group (fig. 6).

\section{Salvage Surgery}

Salvage surgery is regarded as the surgery that is performed after curative radiation or chemoradiation therapy to remove the residual or regrown tumors which have invaded adjacent organs (as described in the Japanese guidelines of esophageal cancer [53, 54]). Salvage surgery is conducted in locally advanced tumors, but adjuvant surgery is conducted in metastatic cancer. Indeed, using the term 'adjuvant' in palliative surgery, even if it is after successful chemotherapy in stage IV gastric cancer, might be criticized. Because, in general, the term 'adjuvant' can be used when the tumor does not exist macroscopically, the term 'adjuvant chemotherapy' is used for chemotherapy when an R0 resection has been performed. In this sense, the term 'adjuvant surgery' could be defined as the curative surgery after CR was detected by chemotherapy in stage IV cancer. Further discussion might be required to determine the most appropriate terminology.

\section{References}

1 GLOBOCAN database. http//www-dep.jarc. fr/globocan/globocan.html.

2 Tajim K: Recent Advances of Cancer in Japan; in Saji S (ed): Recent Advances of Cancer in Asian Countries (commemorative book of the 9th ACOS 2010 in Gifu). Tokyo, Cancer and Chemotherapy, 2010, pp 26-34.

- 3 Yoshida K, Yamaguchi K, Osada S, Kawaguchi Y, Takahashi T, Sakashita F, Tanaka Y: Challenge for a better combination with basic evidence. Int J Clin Oncol 2008;13:212219.

4 Aikou T (ed): Japanese Gastric Cancer Association: Japanese Classification of Gastric Carcinoma. Tokyo, Kanehara Shuppan, 2010.

5 Sano T (ed): Japanese Gastric Cancer Association: Japanese Guideline for Gastric Carcinoma. Tokyo, Kanehara Shuppan, 2010.

-6 Shiraishi N, Yasuda K, Kitano S: Laparoscopic gastrectomy with lymph node dissection for gastric cancer. Gastric Cancer 2006; 9:167-176.
7 Kitano S, Shiraishi N, Uyama I, Sugihara K, Tanigawa N, Japanese Laparoscopic Surgery Study Group: A multicenter study on oncologic outcome of laparoscopic gastrectomy for early cancer in Japan. Ann Surg 2007; 245:68-72.

8 Uyama I, Sakurai Y, Komori Y, Nakamura Y, Syoji M, Tonomura S, Yoshida I, Masui T, Ochiai M: Laparoscopic gastrectomy with preservation of the vagus nerve accompanied by lymph node dissection for early gastric carcinoma. J Am Coll Surg 2005;200: 140-145.

-9 Songun I, Putter H, Kranenbarg EM, Sasako M, van de Velde CJ: Surgical treatment of gastric cancer: 15-year follow-up results of the randomised nationwide Dutch D1D2 trial. Lancet Oncol 2010;11:439-449.

10 Cunningham D, Allum WH, Stenning SP, Thompson JN, Van de Velde CJ, Nicolson M, Scarffe JH, Lofts FJ, Falk SJ, Iveson TJ, Smith DB, Langley RE, Verma M, Weeden S, Chua YJ, MAGIC Trial Participants: Perioperative chemotherapy versus surgery alone for resectable gastroesophageal cancer. N Engl J Med 2006;355:11-20.
1 Macdonald JS, Smalley SR, Benedetti J, Hundahl SA, Estes NC, Stemmermann GN, Haller DG, Ajani JA, Gunderson LL, Jessup JM, Martenson JA: Chemoradiotherapy after surgery compared with surgery alone for adenocarcinoma of the stomach or gastroesophageal junction. N Engl J Med 2001;345: 725-730.

12 Sasako M, Sano T, Yamamoto S, Kurokawa Y, Nashimoto A, Kurita A, Hiratsuka M, Tsujinaka T, Kinoshita T, Arai K, Yamamura Y, Okajima K, Japan Clinical Oncology Group: D2 lymphadenectomy alone or with para-aortic nodal dissection for gastric cancer. N Engl J Med 2008;359:453-462.

13 Sakuramoto S, Sasako M, Yamaguchi T, Kinoshita T, Fujii M, Nashimoto A, Furukawa $\mathrm{H}$, Nakajima $\mathrm{T}$, Ohashi $\mathrm{Y}$, Imamura $\mathrm{H}$, Higashino M, Yamamura Y, Kurita A, Arai K, ACTS-GC Group: Adjuvant chemotherapy for gastric cancer with S-1, an oral fluoropyrimidine. N Engl J Med 2007;357:18101820.

14 Sano T: Adjuvant and neoadjuvant therapy of gastric cancer: a comparison of three pivotal studies. Curr Oncol Rep 2008; 10:191-198. 
$\longrightarrow 15$ Tsuburaya A, Sakamoto J, Morita S, Kodera Y, Kobayashi M, Miyashita Y, Macdonald JS: A randomized phase III trial of post-operative adjuvant oral fluoropyrimidine versus sequential paclitaxel/oral fluoropyrimidine; and UFT versus S1 for T3/T4 gastric carcinoma: the Stomach Cancer Adjuvant Multiinstitutional Trial Group (SAMIT) Trial. Jpn J Clin Oncol 2005;35:672-675.

16 Park YH, Lee JL, Ryoo BY, Ryu MH, Yang SH, Kim BS, Shin DB, Chang HM, Kim TW, Yuh YJ, Kang YK: Capecitabine in combination with Oxaliplatin (XELOX) as a firstline therapy for advanced gastric cancer. Cancer Chemother Pharmacol 2008;61: 623-629.

17 Ohtsu A, Shimada Y, Shirao K, Boku N, Hyodo I, Saito H, Yamamichi N, Miyata Y, Ikeda N, Yamamoto S, Fukuda H, Yoshida S: Randomized phase III trial of fluorouracil alone versus fluorouracil plus cisplatin versus uracil and tegafur plus mitomycin in patients with unresectable, advanced gastric cancer: the Japan Clinical Oncology Group study (JCOG 9205). J Clin Oncol 2003;21: 54-59.

18 Wilson D, Hiller L, Geh I: ECF in gastric cancer. Clin Oncol (R Coll Radiol) 2004;16: 381-382.

19 Cunningham D, Starling N, Rao S, Iveson T, Nicolson M, Coxon F, Middleton G, Daniel F, Oates J, Norman AR, Upper Gastrointestinal Clinical Studies Group of the National Cancer Research Institute of the UK: Capecitabine and oxaliplatin for advanced esophagogastric cancer. N Engl J Med 2008; 358:36-46.

-20 Ajani JA, Moiseyenko VM, Tjulandin S, Majlis A, Constenla M, Boni C, Rodrigues A, Fodor M, Chao Y, Voznyi E, Marabotti C, Van Cutsem E: Clinical benefit with docetaxel plus fluorouracil and cisplatin compared with cisplatin and fluorouracil in a phase III trial of advanced gastric or gastroesophageal cancer adenocarcinoma: the V-325 Study Group. J Clin Oncol 2007;25: 3210-3216.

-21 Overman MJ, Kazmi SM, Jhamb J, Lin E, Yao JC, Abbruzzese JL, Ho L, Ajani J, Phan A: Weekly docetaxel, cisplatin, and 5-fluorouracil as initial therapy for patients with advanced gastric and esophageal cancer. Cancer 2010;116:1446-1453.

-22 Koizumi W, Narahara H, Hara T, Takagane A, Akiya T, Takagi M, Miyashita K, Nishizaki T, Kobayashi O, Takiyama W, Toh Y, Nagaie T, Takagi S, Yamamura Y, Yanaoka K, Orita H, Takeuchi M: S-1 plus cisplatin versus $\mathrm{S}-1$ alone for first-line treatment of advanced gastric cancer (SPIRITS trial): a phase III trial. Lancet Oncol 2008;9:215221.
23 Bang YJ, Van Cutsem E, Feyereislova A, Chung HC, Shen L, Sawaki A, Lordick F, Ohtsu A, Omuro Y, Satoh T, Aprile G, Kulikov E, Hill J, Lehle M, Rüschoff J, Kang YK, ToGA Trial Investigators: Trastuzumab in combination with chemotherapy versus chemotherapy alone for treatment of HER2positive advanced gastric or gastro-oesophageal junction cancer (ToGA): a phase 3, open-label, randomised controlled trial. Lancet 2010;376:687-697.

24 Suzuki T, Tanabe K, Taomoto J, Yamamoto H, Tokumoto N, Yoshida K, Ohdan H: Preliminary trial of adjuvant surgery for advanced gastric cancer. Oncology Lett 2010;1:743-747.

-25 Satoh S, Okabe S, Teramukai S, Hasegawa N, Ozaki S, Ueda A, Tsuji S, Sakabayashi Y, Sakai Y: Early outcome of phase II study of preoperative chemotherapy (CX) with S-1 plus cisplatin for stage IV gastric cancer: 2010 ASCO Annual Meeting Proceedings (abstract 4124). J Clin Oncol 2010;28:15s.

26 Adam R, Aloia T, Lévi F, Wicherts DA, de Haas RJ, Paule B, Bralet M-P, Bouchahda M, Machover D, Ducreux M, Castagne V, Azoulay D, Castaing D: Hepatic resection after rescue cetuximab treatment for colorectal liver metastases previously refractory to conventional systemic therapy. J Clin Oncol 2007;25:4593-4602.

27 Poston GP, Adam R, Alberts S, Curley S, Figueras J, Haller D, Kunstlinger F, Mentha G, Nordlinger B, Patt Y, Primrose J, Roh M, Rougier P, Ruers T, Schmoll HJ, Valls C, Nick Vauthey NJ-N, Cornelis M, Kahan JP: OncoSurge: a strategy for improving resectability with curative intent in metastatic colorectal cancer. J Clin Oncol 2005;23:7125-7134.

28 Adam R, Wicherts DA, de Haas RJ, Ciacio O, Lévi F, Paule B, Ducreux M, Azoulay D, Bismuth H, Castaing D: Patients with initially unresectable colorectal liver metastases: is there a possibility of cure? J Clin Oncol 2009; 27:1829-1835.

29 Song J, Oh SJ, Kang WH, Hyung WJ, Choi $\mathrm{SH}$, Noh SH: Robot-assisted gastrectomy with lymph node dissection for gastric cancer: lessons learned from an initial 100 consecutive procedures. Ann Surg 2009;249: 927-932.

30 Yoshida K, Yamaguchi K, Sakashita F, Tanaka Y, Sanada Y, Takahashi T, Osada S: Complete laparoscopic gastrectomy preserving autonomic nerves in early gastric cancer (in Japanese). Shoukakigeka 2009;32:1-11.

31 Yoshida K, Tanabe K, Ukon K, Hihara J, Ohta $\mathrm{K}$, Toge T: Laparoscopy assisted distal gastrectomy (LADG) preserving autonomic nerves; in Kitajima M and Otani Y (eds): Proceedings of the 6th International Gastric Cancer Congress, Yokohama, 2005, pp 389-393.

32 Ohtani H, Tamamori Y, Noguchi K, Azuma T, Fujimoto S, Oba H, Aoki T, Minami M, Hirakawa K: Meta-analysis of laparoscopyassisted and open distal gastrectomy for gastric cancer. J Surg Res 2010, E-pub ahead of print.
33 Kurokawa Y, Katai H, Fukuda H, Sasako M, Gastric Cancer Surgical Study Group of the Japan Clinical Oncology Group: Phase II study of laparoscopy-assisted distal gastrectomy with nodal dissection for clinical stage I gastric cancer: Japan Clinical Oncology Group study JCOG 0703. Jpn J Clin Oncol 2008;38:501-503.

-34 Kim HH, Hyung WJ, Cho GS, Kim MC, Han SU, Kim W, Ryu SW, Lee HJ, Song KY: Morbidity and mortality of laparoscopic gastrectomy versus open gastrectomy for gastric cancer: an interim report - a phase III multicenter, prospective, randomized trial (KLASS Trial). Ann Surg 2010;251:417-420.

- 35 Kanaya S, Gomi T, Momoi H, Tamaki N, Isobe $\mathrm{H}$, Katayama $\mathrm{T}$, Wada $\mathrm{Y}$, Ohtoshi $\mathrm{M}$ : Delta-shaped anastomosis in totally laparoscopic Billroth I gastrectomy: new technique of intraabdominal gastroduodenostomy. J Am Coll Surg 2002;195:284-287.

- 36 Fujii M, Kochi M, Takayama T: Recent advances in chemotherapy for advanced gastric cancer in Japan. Surg Today 2010;40:295300.

37 Koizumi W, Tanabe S, Saigenji K, Ohtsu A, Boku N, Nagashima F, Shirao K, Matsumura Y, Gotoh M: Phase I/II study of S-1 combined with cisplatin in patients with advanced gastric cancer. Br J Cancer 2003;89:2207-2212.

38 Komatsu Y, Yuki S, Tateyama M, Kudo M, Asaka M: Irinotecan plus oral S-1 in patients with advanced gastric cancer-biweekly IRIS regimen. Gan to Kagaku Ryoho 2006;33 (suppl 1):131-134.

39 Yoshida K, Hirabayashi N, Takiyama W, Ninomiya M, Takakura N, Sakamoto J, Nishiyama M, Toge T: Phase I study of combination therapy with S-1 and docetaxel (TXT) for advanced or recurrent gastric cancer. Anticancer Res 2004;24:1843-1852.

40 Yoshida K, Ninomiya M, Takakura N, Hirabayashi N, Takiyama W, Sa to Y, Todo S, Terashima M, Goto M, Sakamoto J, Nishiyama M: Phase II study of docetaxel and S-1 combination therapy for advanced or recurrent gastric cancer. Clin Cancer Res 2006;12: 3402-3407.

41 Wada Y, Yoshida K, Suzuki T, Mizuiri H, Konishi K, Ukon K, Tanabe K, Sakata Y, Fukushima M: Synergistic effects of docetaxel and S-1 by modulating the expression of metabolic enzymes of 5-fluorouracil in human gastric cancer cell lines. Int J Cancer 2006;119:783-791.

42 Shigematsu H, Yoshida K, Sanada Y, Osada S, Takahashi T, Wada Y, Konishi K, Okada M, Fukushima M: Rapamycin enhances chemotherapy-induced cytotoxicity by inhibiting the expressions of TS and ERK in gastric cancer cells. Int J Cancer 2010;126:27162725. 
43 Imamura H, Iishi H, Tsuburaya A, Hatake K, Imamoto $\mathrm{H}$, Esaki $\mathrm{T}$, et al: Randomized phase III study of irinotecan plus S-1 (IRIS) versus $\mathrm{S}-1$ alone as first-line treatment for advanced gastric cancer (GC0301/TOP002). Gastric Cancer 2011;14:72-80.

44 Kim YH, Koizumi W, Lee KH, Kishimoto T, Chung HC, Hara T, Cho JY, Nakajima T, Kim HK, Fujii M: Japan Clinical Cancer Research Organization (JACCRO) and Korean Cancer Study Group (KCSG) inter-group study: randomized phase III study of S-1 alone versus S-1 + docetaxel in the treatment for advanced gastric cancer: the START trial. Gastrointestinal Cancers Symposium General Session (abstract 7). J Clin Oncol 2011; 29(suppl 4).

-45 Tanabe K, Suzuki T, Tokumoto N, Yamamoto $\mathrm{H}$, Yoshida $\mathrm{K}$, Ohdan $\mathrm{H}$ : Combination therapy with docetaxel and S-1 as a first-line treatment in patients with advanced or recurrent gastric cancer: a retrospective analysis. World J Surg Oncol 2010;8:40.
46 Schuhmacher C, Gretschel S, Lordick F, Reichardt P, Hohenberger W, Eisenberger CF, Haag C, Mauer ME, Hasan B, Welch J, Ott K, Hoelscher A, Schneider PM, Bechstein W, Wilke H, Lutz MP, Nordlinger B, Van Cutsem E, Siewert JR, Schlag PM: Neoadjuvant chemotherapy compared with surgery alone for locally advanced cancer of the stomach and cardia: European Organisation for Research and Treatment of Cancer Randomized Trial 40954. J Clin Oncol 2010, Epub ahead of print.

47 Wada Y, Yoshida K, Hihara J, Jyunya T, Suzuki T, Mizuiri H, Konishi K, Ukon K, Tanabe K: A specific neutrophil elastase inhibitor, sivelestat, suppresses the growth of gastric carcinoma cells by preventing the release of TGF- $\alpha$. Cancer Sci 2006;97:1037-1043.

48 Adam R, Delvart V, Pascal G, Valeanu A, Castaing D, Azoulay D, Giacchetti S, Paule B, Kunstlinger F, Ghémard O, Levi F, Bismuth $\mathrm{H}$ : Rescue surgery for unresectable colorectal liver metastases downstaged by chemotherapy a model to predict long-term survival. Ann Surg 2004;240:644-658.

-49 Adam R, Wicherts DA, de Haas RJ, Aloia T, Lévi F, Paule B, Guettier C, Kunstlinger F, Delvart V, Azoulay D, Castaing D: Complete pathologic response after preoperative chemotherapy for colorectal liver metastases: myth or reality? J Clin Oncol 2008;26:16351641.
50 Adam R, de Haas RJ, Wicherts DA, Aloia T, Delvart V, Azoulay D, Bismuth H, Castaing D: Is hepatic resection justified after chemotherapy in patients with colorectal liver metastases and lymph node involvement? J Clin Oncol 2008;26:3672-3680.

51 Nuzzo G, Giuliante F, Ardito F, Vellone M, Pozzo C, Cassano A, GiovanniniI, Barone C: Liver resection for primarily unresectable colorectal metastases downsized by chemotherapy. J Gastrointest Surg 2007;11:318324.

52 Saif MW: Secondary hepatic resection as a therapeutic goal in advanced colorectal cancer. World J Gastroenterol 2009; 15:38553864.

53 Makuuchi H (ed): The Japan Esophageal Society: Japanese Guideline for Diagnosis and Treatment for Esophageal Cancer.. Tokyo, Kanehara Shuppan, 2007, pp 70-71.

54 Nakamura T, Hyashi K, Ota M, Eguchi R, Ide H, Takasaki K, Mitsuhashi N: Salvage esophagectomy after definitive chemotherapy and radiotherapy for advanced esophageal cancer. Am J Surg 2004;188:161-166. 